\title{
Efficacy and safety analysis on dendritic cell-based vaccine-treated high-grade glioma patients: a systematic review and meta-analysis
}

This article was published in the following Dove Press journal:

OncoTargets and Therapy

\author{
Changling $\mathrm{Li}^{1, *}$ \\ Ting Liu',* \\ Bo Zhou ${ }^{3}$ \\ Yubin Zhou ${ }^{4}$ \\ Huiying Yu' \\ Yun Sun ${ }^{2}$ \\ 'Department of Experimental \\ Medicine, Northern Hospital, \\ Shenyang II00I6, China; ${ }^{2}$ Department \\ of General Practice, The Second \\ Hospital of Dalian Medical University, \\ Dalian II 6023, China; ${ }^{3}$ Department of \\ Clinical Epidemiology and Evidence- \\ based Medicine, The First Affiliated \\ Hospital, China Medical University, \\ Shenyang II 000I, China; ${ }^{4}$ Department \\ of Oncology, The People's Hospital of \\ China Medical University, Shenyang \\ II00I5, China \\ *These authors contributed equally \\ to this work
}

Background: Dendritic cell (DC)-based vaccine is a promising therapy for high-grade gliomas (HGGs); however, its actual effectiveness still remains controversial. This meta-analysis aims to extensively evaluate the efficacy and safety of DC vaccine for HGG patients.

Methods: We systematically searched PubMed, the Cochrane Library, EMBASE, Medline, and Web of Science for relevant parallel randomized controlled trials (RCTs) and properly controlled non-randomized studies (NRS) published in English. Two investigators reviewed all the texts and extracted information regarding overall survival (OS), progression-free survival (PFS), and adverse events (AEs) from eligible studies. Sensitivity analyses and subgroup analyses were also conducted.

Results: Of 353 suitable studies, 13 studies (three RCTs and ten NRS) involving 944 patients were finally included. Compared to the control therapy group (CT group), the DC group showed better OS and PFS without serious AEs. Subgroup analysis showed that trials designed as NRS obtained better results in the DC group in this study; however, no specific subgroup regarding dosages, cycles or injection routes was found to be superior in the DC group compared to the CT group. Conclusion: DC vaccine can significantly improve OS and PFS, with acceptable toxicity, of HGG patients. Nevertheless, further studies are needed to verify this conclusion.

Keywords: dendritic cell, vaccine, glioblastoma multiforme, high-grade gliomas, overall survival, progression-free survival

\section{Introduction}

High-grade gliomas (HGGs) generally consist of anaplastic astrocytomas (WHO grade III) and glioblastoma multiforme (GBM; WHO grade IV), anaplastic oligodendrogliomas (WHO grade III), and the rare anaplastic oligoastrocytomas (WHO grade III), among which, GBM is the most frequent and common type of HGG in primary malignant brain tumors, with an incidence of 3-4 per 100,000, accounting for $15.6 \%$ of all primary brain tumors and $45.2 \%$ of primary malignant brain tumors. ${ }^{1}$ The current standard treatment for HGG patients includes maximal surgical resection, followed by concurrent high-dose radiation and temozolomide (TMZ) chemotherapy. ${ }^{2}$ However, prognosis of GBM patients remains dismal, with a median survival of 15 months $^{3}$ and only $25 \%$ surviving at 2 years after initial diagnosis. ${ }^{4}$ Therefore, new treatment modalities are urgently needed.

Autologous dendritic cell (DC)-based immunotherapy is one of the promising, novel approaches for HGG treatment. ${ }^{5}$ DCs are a specialized family of professional antigen presenting cells with the broadest range of antigen presentation and unique ability to initiate and maintain primary immune responses when pulsed with tumor
Correspondence: Huiying Yu Department of Experimental Medicine,

Shenyang II0016, China

(elo

Yun Sun

Department of General Practice, The Second Hospital of Dalian Medical University, 467 Zhongshan Road, Dalian II6023, China

Tel +86 I 38426 I 6867

Email byqf_20II@I63.com

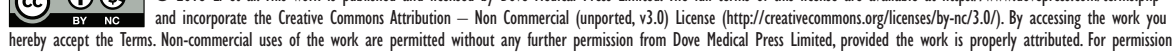
for commercial use of this work, please see paragraphs 4.2 and 5 of our Terms (https://www.dovepress.com/terms.php). 
associated antigens (TAAs). ${ }^{6,7}$ As in vaccine preparation, DCs are extracted from the patient, cultured ex vivo, loaded with TAAs, and subsequently reintroduced into the patient to facilitate antigen-specific T-cell activation. ${ }^{8}$

During the past few decades, DC vaccines have been clinically investigated in a vast range of malignancies, including prostate cancer, renal cell carcinoma, melanoma, and even glioma. Regarding HGGs (malignant glioma), multiple Phase I/II trials have been reported; however, the objective response rate was only $15.6 \% .{ }^{9}$ Conversely, two meta-analysis published in 2014 indicated improved overall survival (OS) and progression free-survival (PFS) were obtained through DC vaccination in HGG patients. ${ }^{10,11}$ With more clinical trials completed in the past few years, we are trying to synthesize the data for the efficacy and safety of DC vaccine application in HGG patients with freshly updated retrievals from both randomized clinical trials (RCTs) and properly controlled non-randomized controlled studies (NRS).

\section{Methods}

Since this study is a meta-analysis of previously published studies, ethical approval and patient consent were not required.

This study was conducted and reported in adherence to Preferred Reporting Items for Systematic Reviews and Meta-analysis. ${ }^{12}$ The PRISMA checklist was reported in Figure S1.

\section{Literature search strategy}

A systematic search of several online databases (PubMed, EMBASE, ISI Web of Science and Cochrane Library) was performed for original articles published in English language up to June 15, 2018 relevant to DC vaccine for HGGs. Clinical trials registered on the website ClinicalTrials. gov were also explored. The following search terms were applied to identify relevant studies: "High-grade gliomas" or HGGs or glioblastoma or GBM or "anaplastic astrocytomas" OR “anaplastic oligodendrogliomas” OR "anaplastic oligoastrocytomas", and "dendritic cell" or DC. Results from these databases were imported into the software of Endnote X7.7 for duplication checking to obtain a list of unique articles for subsequent screening. Gray literature was not included in the present analysis.

For Medline, we used the following search strategies, Search (()(()(()(glioma OR “Anaplastic Astrocytoma” OR "Glioblastoma Multiforme” OR "High-grade glioma” OR astrocytomas OR oligodendrogliomas)) AND dendritic)) NOT ((mice OR animal OR rats OR murine)))) AND
English[Language])) NOT ((“in vitro" [Title/Abstract]) OR "cell line" [Title/Abstract]))) NOT ((review [Publication Type]) OR review).

\section{Selection criteria}

The following criteria were applied when considering studies for this meta-analysis.

\section{Types of studies}

The meta-analysis considered studies evaluating the effectiveness or efficacy of DC vaccine for patients with HGGs. The studies must have compared the intervention with no intervention or with a control intervention. RCTs or properly controlled NRS were eligible for inclusion.

\section{Types of participants}

Patients with primary or recurrent HGGs were included.

\section{Types of interventions}

Patients in the treatment group must have received DC vaccination. Patients in the control group must have been treated with conventional therapy without DC vaccine.

\section{Types of outcome measures}

Results must have included quantitative data for outcomes measured. The primary outcomes were OS and PFS. The secondary outcome was treatment-related adverse events (AEs), which included treatment-related withdrawals and discontinuations.

Conference abstracts and other forms of summary publication were excluded. In the case of multiple studies apparently based on the same population, only the study with the largest number of participants was included.

\section{Data collection}

References were managed using EndNote X7.7 software (Thomson Reuters, New York, NY, USA). Two authors (CLL, TL) independently screened studies identified in literature searches. Discrepancies were arbitrated by two other authors (BZ, YZ). Two authors (CLL, TL) independently extracted data from included studies using a predefined template. BZ and YZ checked the extracted data against the original studies.

Survival data and AEs were taken directly from tables or the text whenever possible; if such data were presented only in Kaplan-Meier curves, they were read by the Engauge Digitizer version 10.4 (free software downloaded from http://sourceforge.net). 


\section{Assessment of methodological quality of included studies}

For the RCTs and NRS, Cochrane bias assessment tool and Newcastle-Ottawa scale ${ }^{13}$ (NOS) were applied, respectively. Two authors (CLL and TL) independently assessed methodological quality of included studies, Discrepancies were arbitrated by HYY and YS.

\section{Data synthesis and analysis}

Statistical analysis was mainly performed using STATA SE (StataCorp LP, College Station, TX, USA). Pooled RRs using the Mantel-Haenszel method were calculated for dichotomous data. The homogeneity of the effect size across studies was tested using Q statistics, $I^{2}$ statistic was also used to assess statistical heterogeneity in the meta-analysis (high heterogeneity $>50 \%$; low heterogeneity, $<50 \%$ ). Data were analyzed using fixed-effects models when $P>0.10$ for the Q statistic; otherwise random-effects models were used. ${ }^{14}$ For the meta-analysis of each outcome, we conducted preplanned sensitivity analyses restricted to trials that included the efficacy of DC. Publication bias was assessed using Begg's funnel plots test ${ }^{15}$ and Egger's regression test, ${ }^{16}$ when studies included were more than ten. ${ }^{17} P$-value $<0.05$ was considered to be significant, except where otherwise specified.

\section{Results}

\section{Study selection}

A total of 353 potentially eligible studies were identified and reviewed. According to inclusion criteria, 241 studies remained after removing the duplicates. Screening of the titles and abstracts led to a final set of 42 studies that were read in full. Of these, 25 studies were excluded because they were not appropriately controlled, and four other studies were excluded due to absence of data for analysis. Eventually, three $\mathrm{RCTs}^{18-20}$ and ten NRS, including five non-randomized controlled trials, ${ }^{21-25}$ four historically controlled studies, ${ }^{26-29}$ and one cohort study, ${ }^{30}$ involving 307 DC-vaccinated (DC group) and 637 non-DC-vaccinated (CT group: control therapy group) patients, were included in the meta-analysis. The detailed selection process was described in Figure 1, according to the PRISMA Statement for reviews and meta-analysis. ${ }^{31}$

\section{Studies' characteristics}

The characteristics of the 13 included studies were described in Table 1, and the outcome data for OS and PFS were presented in Table 2.
Five studies were from America, four from Europe, and the rest from Asia. All studies enrolled patients with HGGs of grade III anaplastic astrocytomas (AA), and/or IV (GBM). One cohort study, ${ }^{30}$ two pilot studies, ${ }^{21,26}$ four Phase I trials, ${ }^{22,25,27,29}$ three Phase II trials, ${ }^{18-20}$ and three Phase I/II trials were included in these studies. ${ }^{23,24,28}$ Most of the studies enrolled patients with Karnofsky performance scale (KPS) score of $\geq 60,{ }^{20,22,23,25,27}$ two studies with KPS score of $\geq 70,{ }^{19,28}$ and only one study with KPS score of $\geq 80 .{ }^{29}$ However, there were still five studies without inclusion criteria for KPS score or relative data not available. ${ }^{18,21,24,26,30}$ All studies contained at least two arms, one arm was conventional treatment, such as surgery, radiation, and TMZ chemotherapy, while the other arm had the addition of DC vaccination. For 7/13 studies, surgery, radiation, and chemotherapy were applied in both arms. ${ }^{18-20,22,24,26,27,29}$ Surgery and radiation were applied in two studies. ${ }^{21,28}$ In a non-RCT study, only chemotherapy was used as the control arm, ${ }^{23}$ while in the cohort study, re-radiation therapy (always concomitant with re-operation) was used as the control arm and re-operation plus DC vaccine was used as the treatment arm. ${ }^{30}$

The activation of DCs was achieved in different ways in different studies. Although autologous tumor lysates (ATL) were commonly used to activate DCs in these studies, ${ }^{18-21,24,25,27}$ HLA-1-eluted peptides, ${ }^{23}$ and acid eluted MHC-I enriched peptides were also alternatives to pulsed DCs. ${ }^{22}$ Autologous glioblastoma stem cell $\mathrm{mRNA}^{26}$ and cytomegalovirus pp $65 \mathrm{mRNA}^{29}$ transfected DCs were administered in two other studies.

The dosage of DCs injected ranged from $10^{6}-10^{8}$, and the vaccination cycles also varied greatly in different studies. The injection routes of DC administration mainly included intradermal (ID), ${ }^{22,24-27,29}$ intratumoral (IT), ${ }^{24}$ subcutaneous (SC), ${ }^{19-21,28}$ and inguinal lymph node injection. ${ }^{18}$

\section{OS}

OS was assessed at the time point of 0.5 year, 1 year, 2 years, 3 years, 4 years, and 5 years, as shown in Table 3 (forest plots were included in Figure S2). No heterogeneity was observed, and fixed-effects models were used. We found that in all of the time points specified, OS was significantly better in DC group than that in CT group, except at the time point of half a year $(P=0.391$, pooled $\mathrm{RR}=1.058,95 \%$ $\mathrm{CI}=0.930-1.203$ ).

\section{PFS}

PFS analysis was performed at the time point of 0.5 year, 1 year, 2 years, 3 years, and 4 years (data were shown in Table 4 


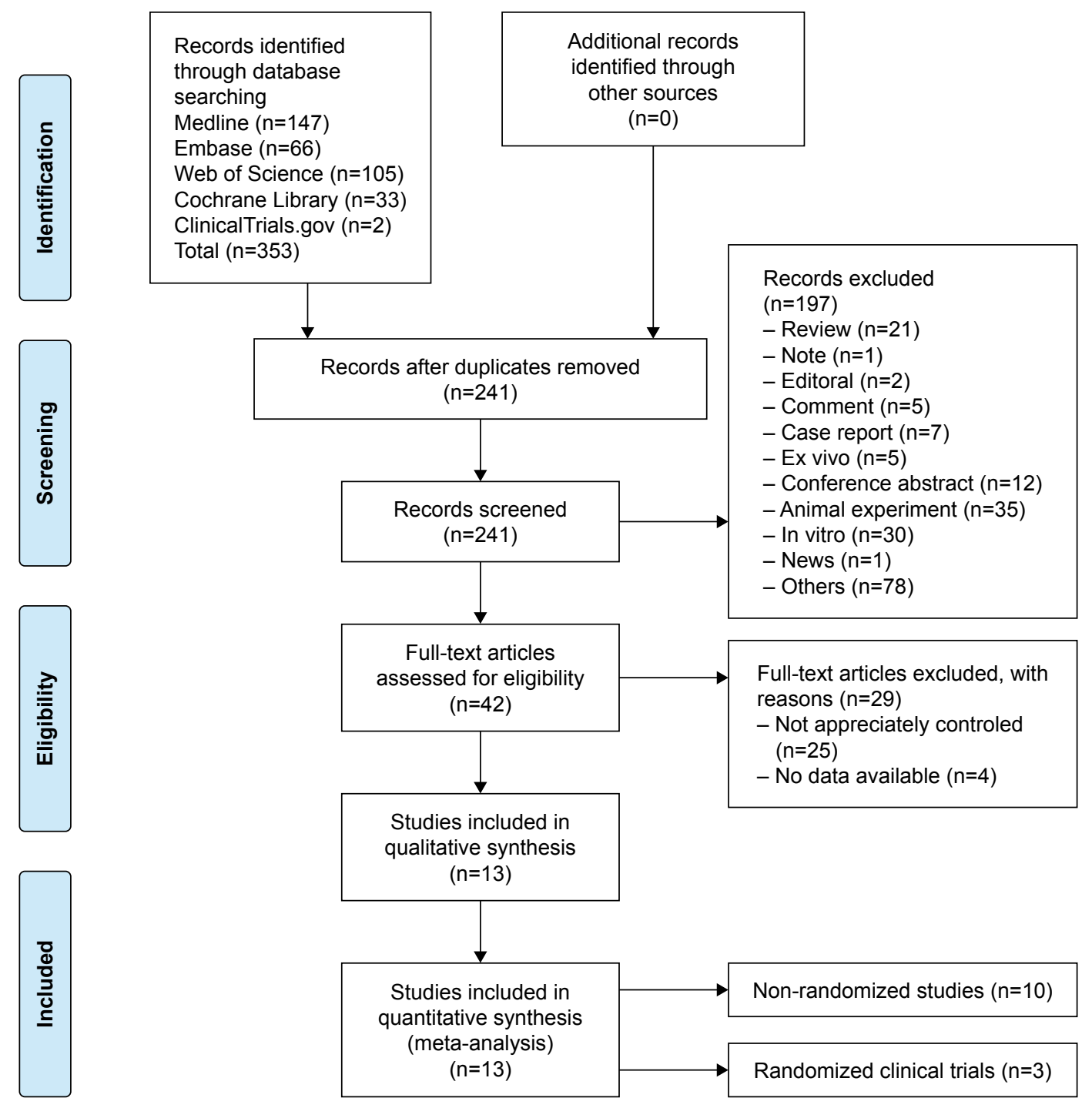

Figure I Study selection process.

and forest plots were included in Figure S3). No advantages were observed in DC group in both 0.5-year PFS and 1-year PFS, although different models were used. In contrast, significantly better PFS data were found in DC group compared with CT group from the time point of 2 years $(P=0.000$, pooled $\mathrm{RR}=8.592,95 \% \mathrm{CI}=2.944-25.077), 3$ years $(P=0.006$, pooled $\mathrm{RR}=9.302,95 \% \mathrm{CI}=1.924-44.969)$, and 4 years $(P=0.039$, pooled $\mathrm{RR}=8.017,95 \% \mathrm{CI}=1.109-57.950)$.

\section{Subgroup analysis}

Subgroup analysis was conducted according to regions (America vs Asia vs Europe), study design (NRS vs RCTs), method of DC activation (peptides vs ATL vs DNA constructs vs fusion of tumor cell lines), dosages $\left(<2 \times 10^{7}\right.$ vs $\geq 2 \times 10^{7}$ ), cycles ( $<4$ vs $\geq 4$ ), and route of injections (ID vs SC). Results were only reported for 1-year OS, 2-year OS, and 3-year OS, as shown in Table 5. Studies published in America showed significant enhancement with DC vaccination in both 2-year $\mathrm{OS}(P<0.001$, pooled $\mathrm{RR}=2.488$, 95\% CI $=1.656-3.738)$ and 3-year OS $(P<0.001$, pooled $\mathrm{RR}=4.574,95 \% \mathrm{CI}=2.312-9.048$ ); however, studies published in Asia also obtained better results in DC group in 3-year OS analysis ( $P=0.001$, pooled $\mathrm{RR}=12.141,95 \%$ $\mathrm{CI}=2.603-56.616)$. NRS indicated significant enhancement in DC group in both 1-year OS $(P=0.018$, pooled $\mathrm{RR}=1.226,95 \% \mathrm{CI}=1.036-1.450), 2$-year OS $(P<0.001$, pooled $\mathrm{RR}=1.806,95 \% \mathrm{CI}=1.361-2.395)$, and 3-year OS $(P=0.001$, pooled $\mathrm{RR}=2.678,95 \% \mathrm{CI}=1.730-4.145)$. Different types of activation of DCs showed significant difference between DC group and CT group in 2-year OS, except for peptides' activation ( $P=0.080$, pooled $\mathrm{RR}=1.983,95 \%$ $\mathrm{CI}=0.922-4.266$ ), perhaps due to the limited study numbers 


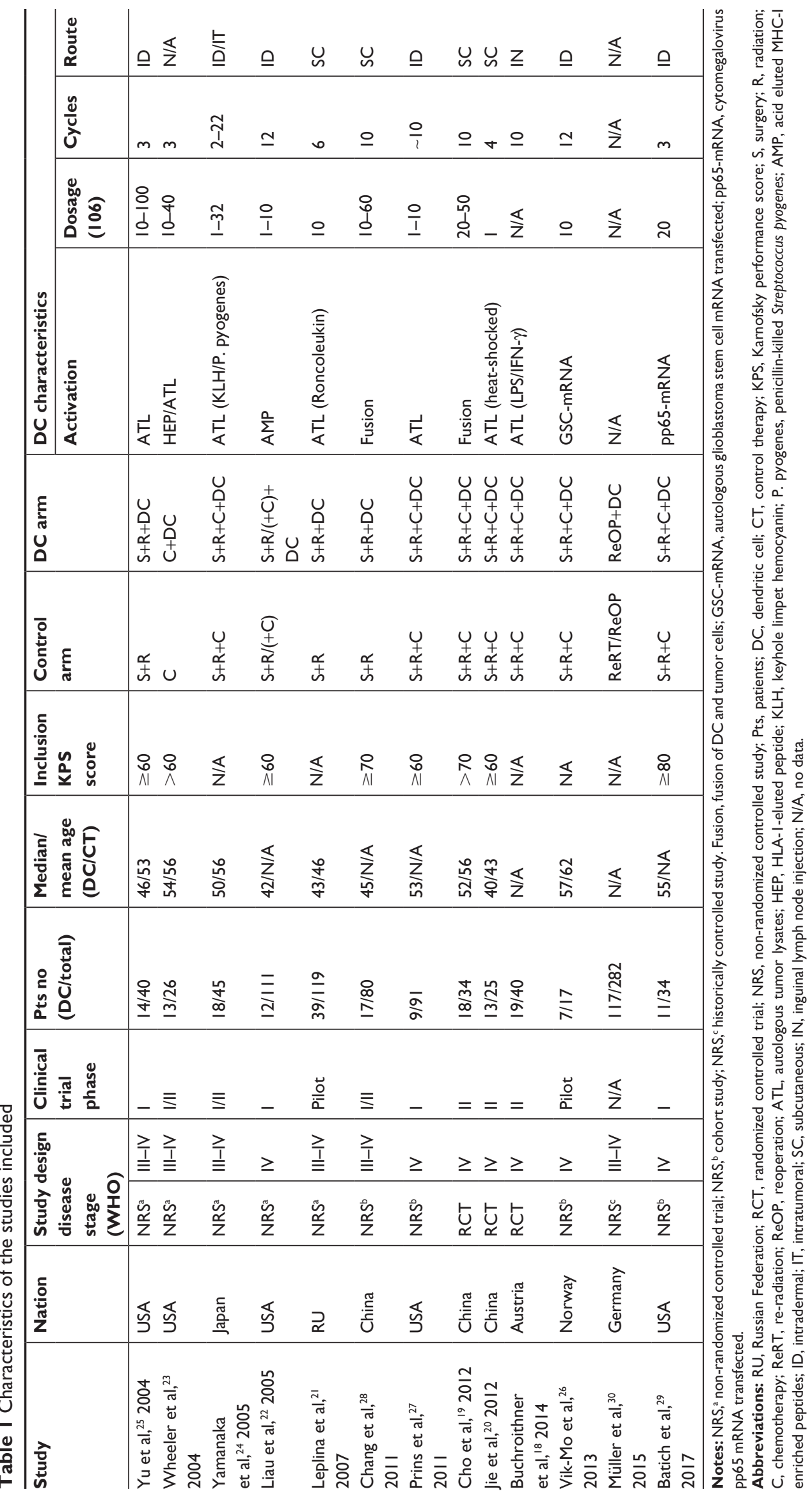




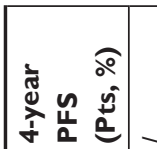

을

๖゚

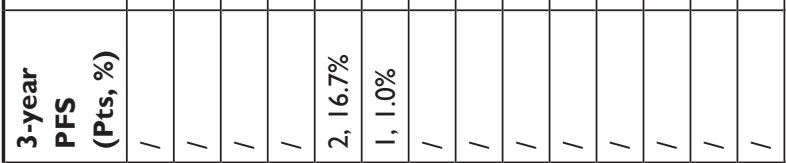

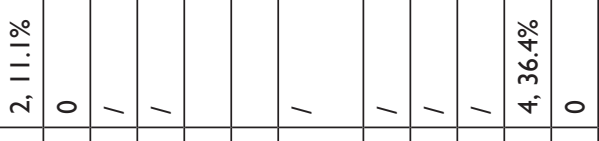

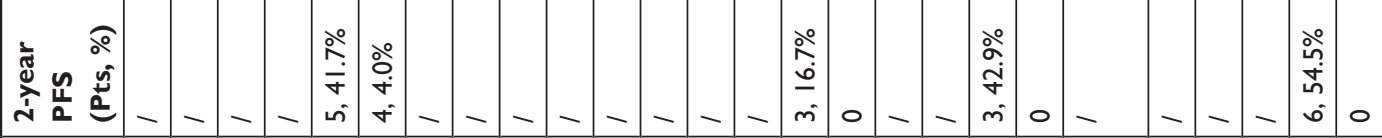

\begin{tabular}{|c|c|c|c|c|c|c|c|c|c|c|c|c|c|c|c|c|c|c|c|c|c|c|c|c|c|c|}
\hline 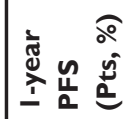 & - & - & - & - & $\begin{array}{l}\text { ○̊ } \\
\text { مீं } \\
\text { á }\end{array}$ & 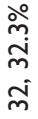 & - & - & - & - & - & - & - & - & $\begin{array}{l}\stackrel{0}{\circ} \\
\infty \\
\text { m } \\
\text { Ṅ }\end{array}$ & $\begin{array}{l}\stackrel{\circ}{m} \\
\frac{\infty}{\infty} \\
m\end{array}$ & - & - & $\begin{array}{c}\stackrel{\circ}{N} \\
\stackrel{2}{\infty} \\
0 \\
0\end{array}$ & $\begin{array}{l}\stackrel{\circ}{\circ} \\
\stackrel{\circ}{0} \\
-\end{array}$ & - & - & - & - & $\stackrel{\substack{N \\
N}}{\stackrel{\infty}{N}}$ & $\frac{\stackrel{\circ}{N}}{\frac{\pi}{n}}$ \\
\hline
\end{tabular}

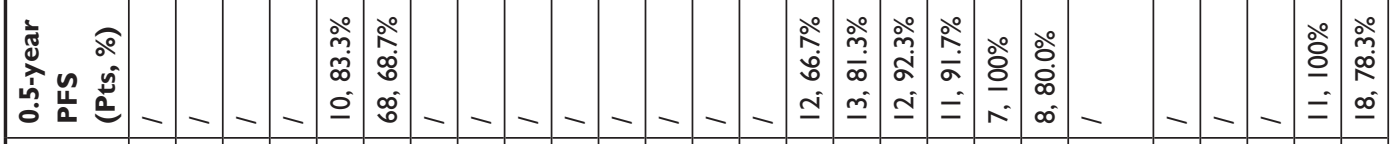

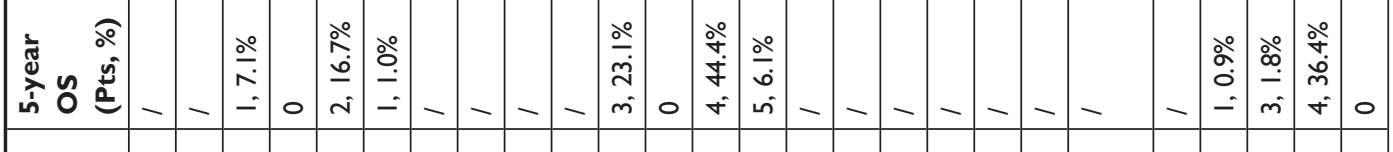

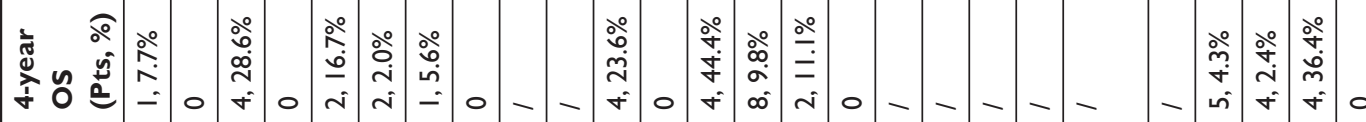

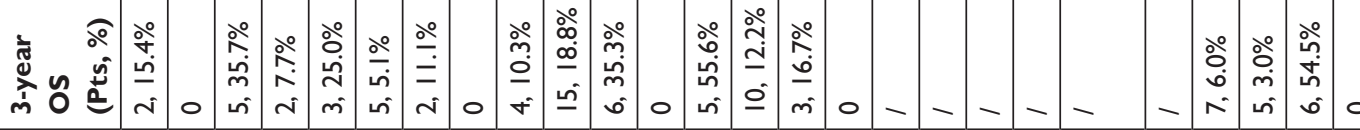

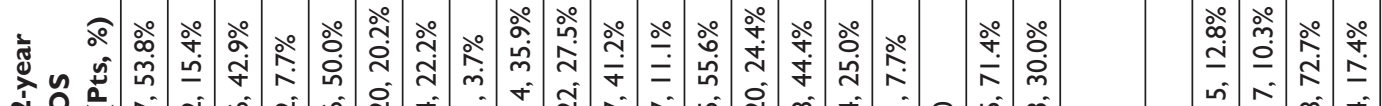
今 О ஓ ஓ

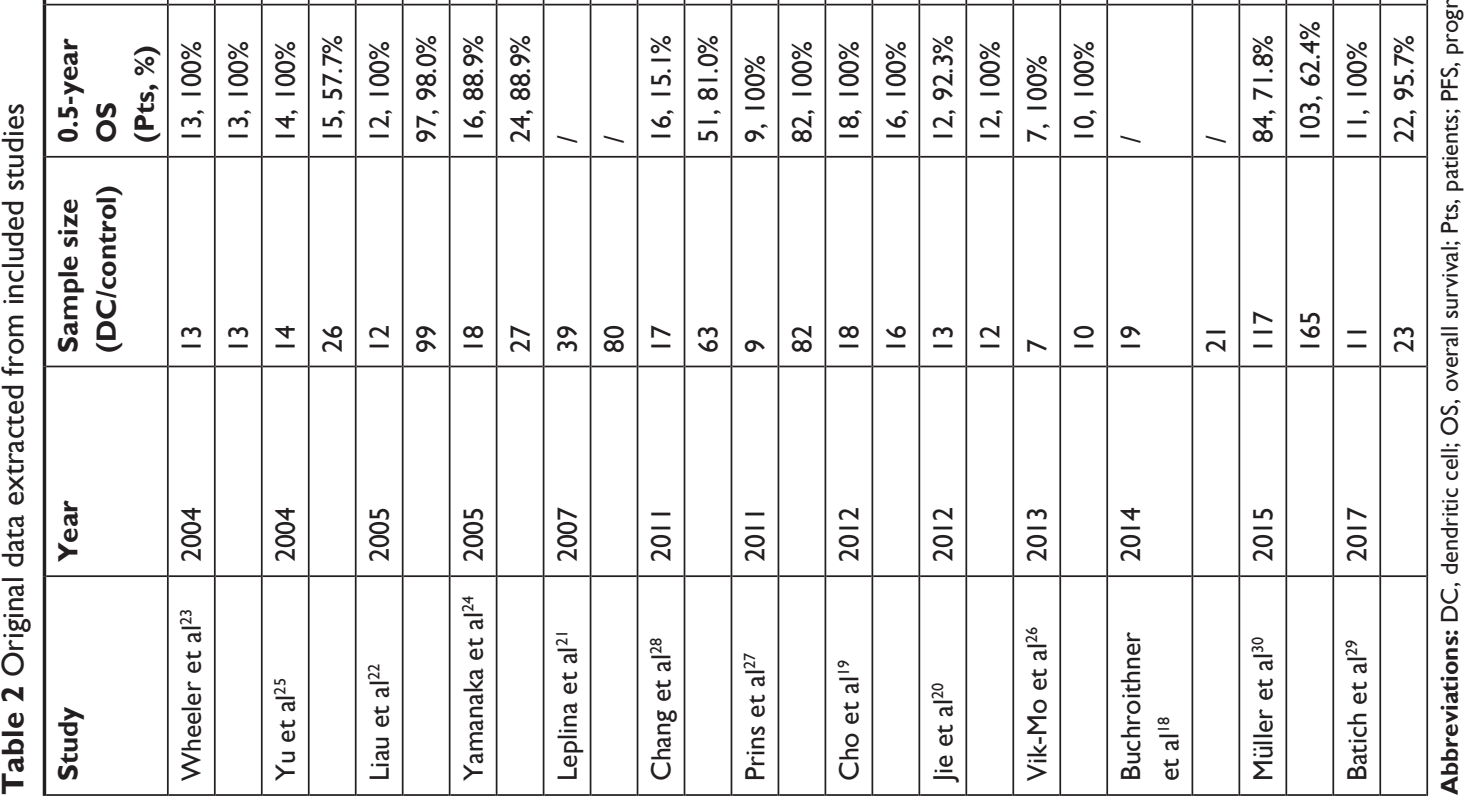



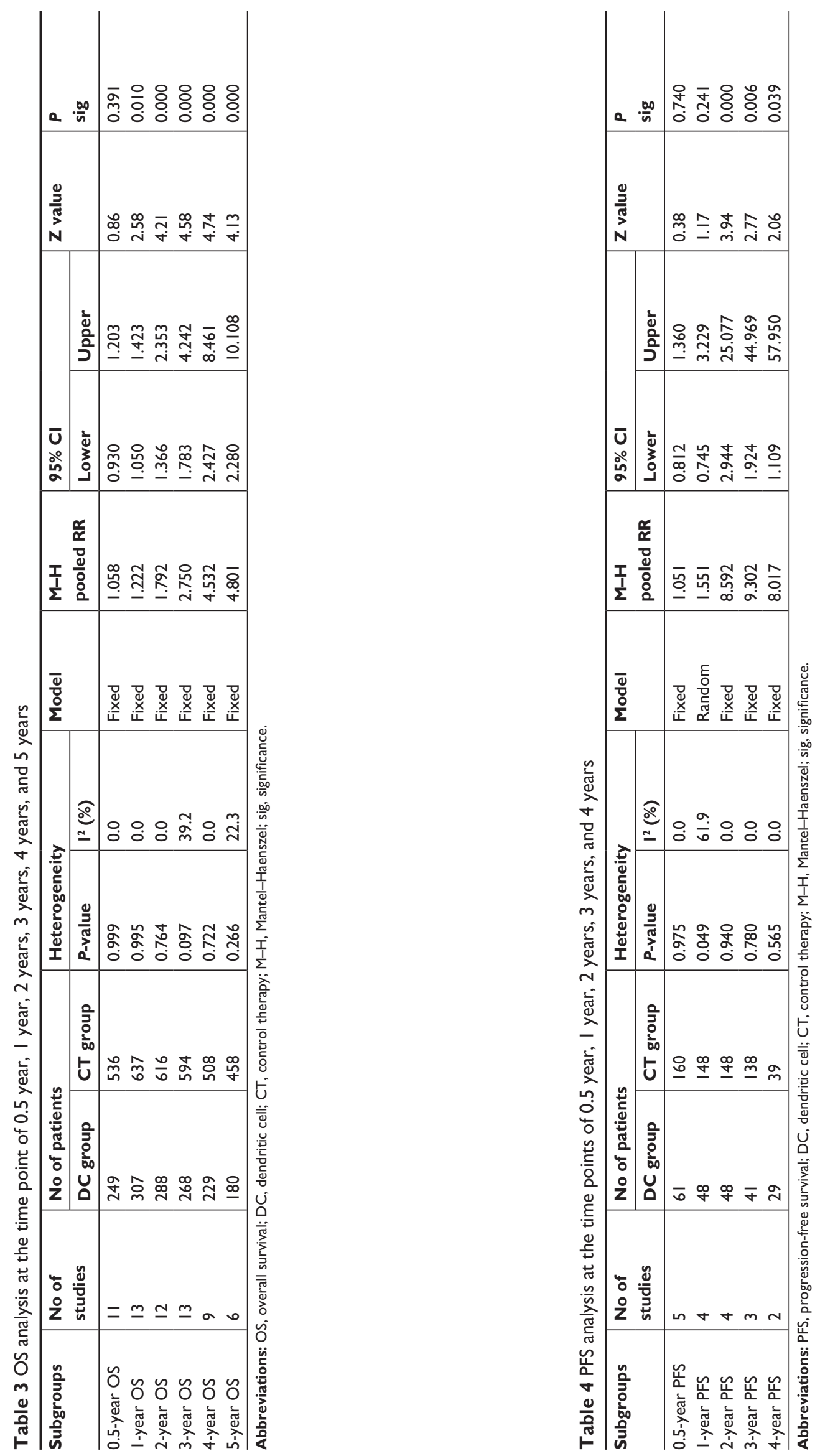


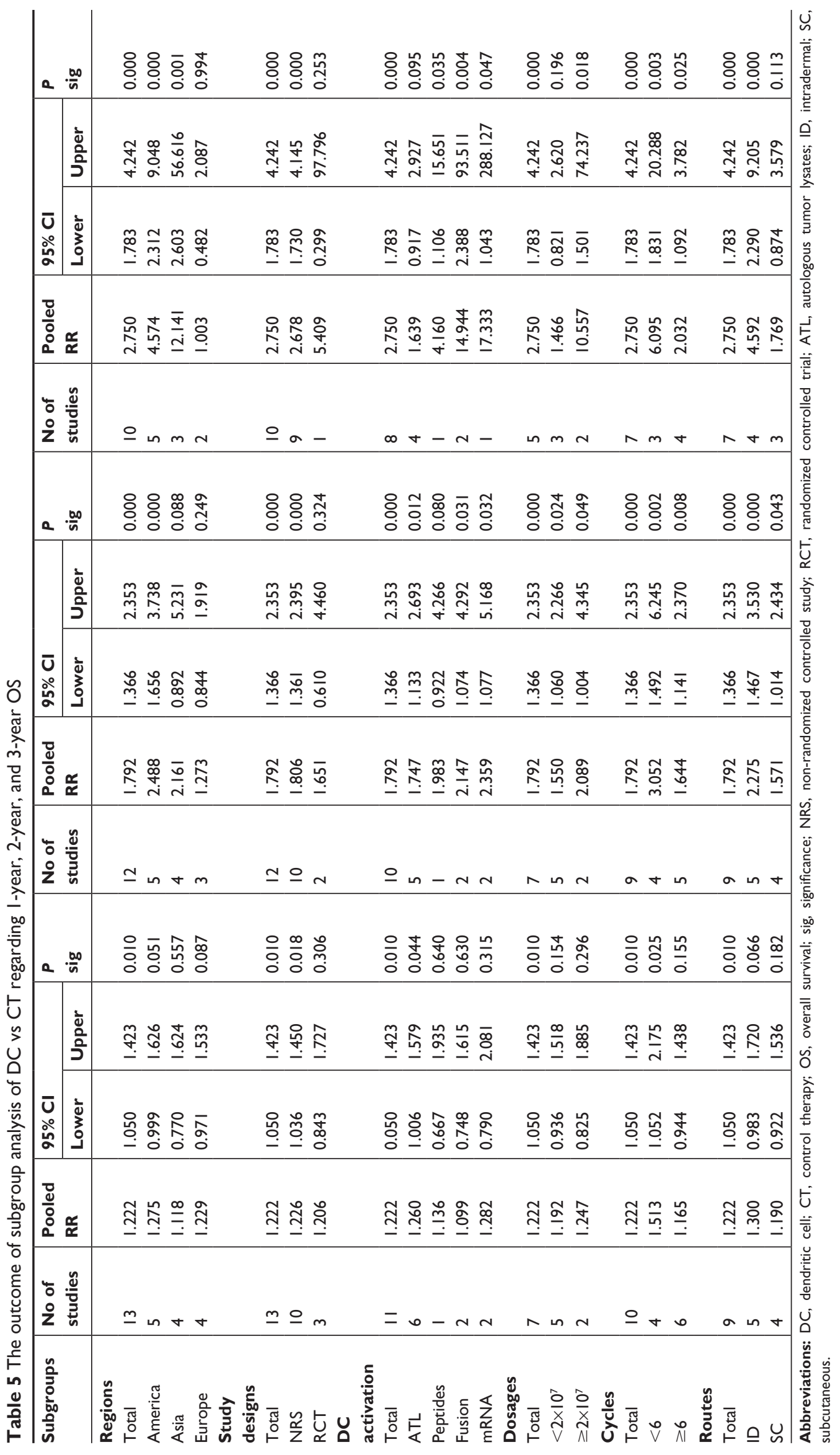


(only one) in this group. No specific dosages, cycles or injection routes were found to be superior in the subgroup analysis, since significant difference between DC group and CT group regarding 2-year OS was found in all the groups within these subgroups.

\section{AEs}

The most frequent AEs were low-grade fever, fatigue, and myalgia. ${ }^{20,22,25-27}$ Injection site reactions, including erythema, pain, and itching, were reported in four studies. ${ }^{22,24,25,27}$ Nausea, vomiting, constipation, and diarrhea were recorded in three studies. ${ }^{22,26,27}$ Severe vaccine-related AEs were only reported in two studies. Chang et al reported Grade III (3/17) and Grade IV (2/17) lymphopenia in DC group, ${ }^{28}$ while Batich et al noted only one Grade III AE attributable to GM-CSF administration. ${ }^{29}$ No death related to DC vaccination was reported in the included studies.

\section{Risk of bias}

Three RCT studies were assessed by Cochrane risk of bias tool with Revman 5.3. As shown in Figure 2, most of the judgements for the three RCT studies were low risk of bias or unclear, with only one high risk of bias reported for Buchroithner et al. In that trial, data were not completely documented. ${ }^{18}$

NRS was assessed by $\operatorname{NOS}^{13}$ as shown in Table 6, most of the studies scored more than six stars, indicating low risk of bias, with only one cohort study scoring five stars. ${ }^{30}$

\section{Sensitivity analysis}

Sensitivity analysis was performed to explore an individual study's influence on the pooled results by deleting one single study each time from pooled analysis. Regarding 0.5-year OS, 1-year OS, 2-year OS, 3-year OS, 4-year OS, and 5-year OS, the results showed that no substantial change
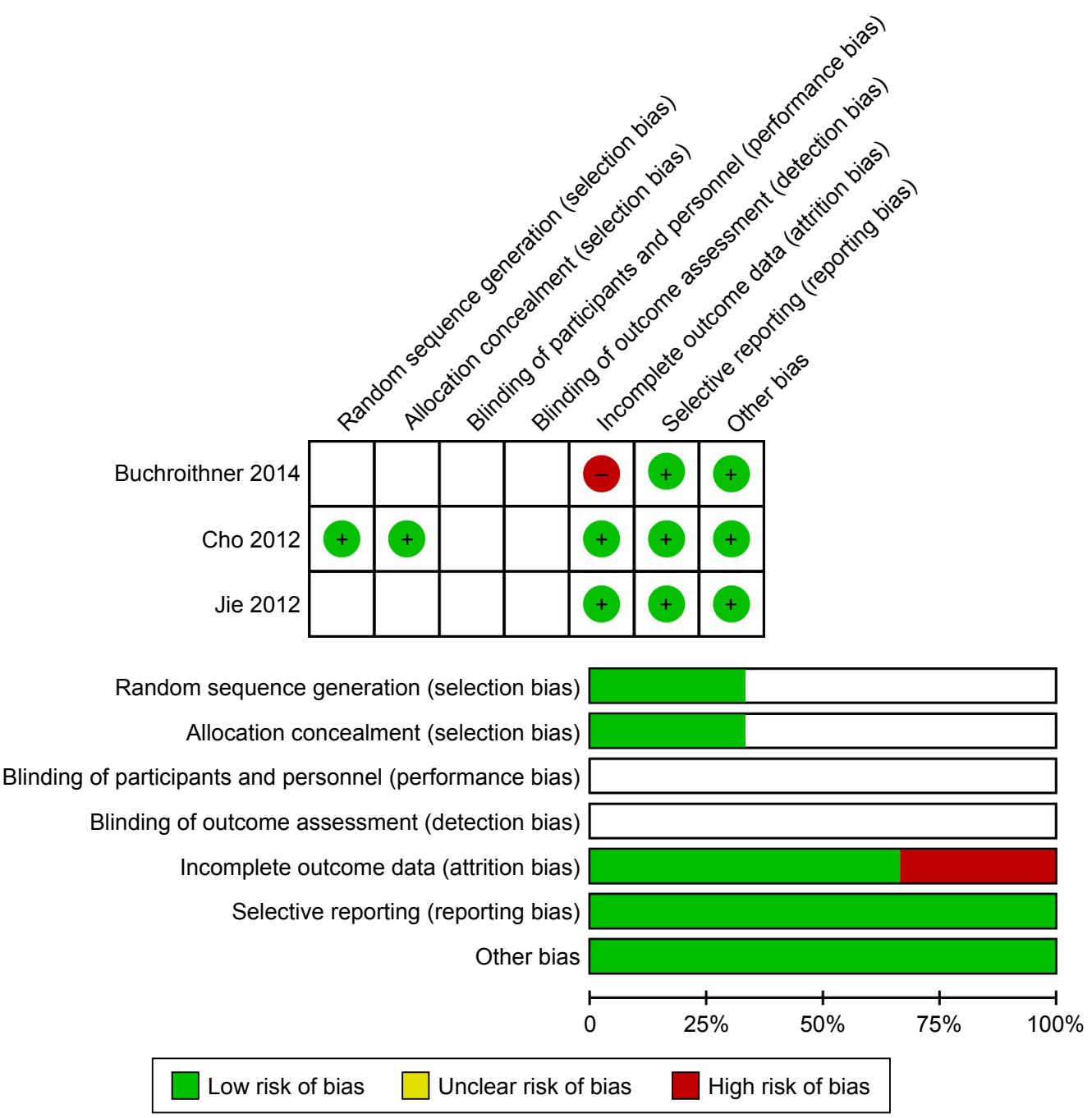

Figure 2 Risk of bias analysis for randomized clinical trials included. 


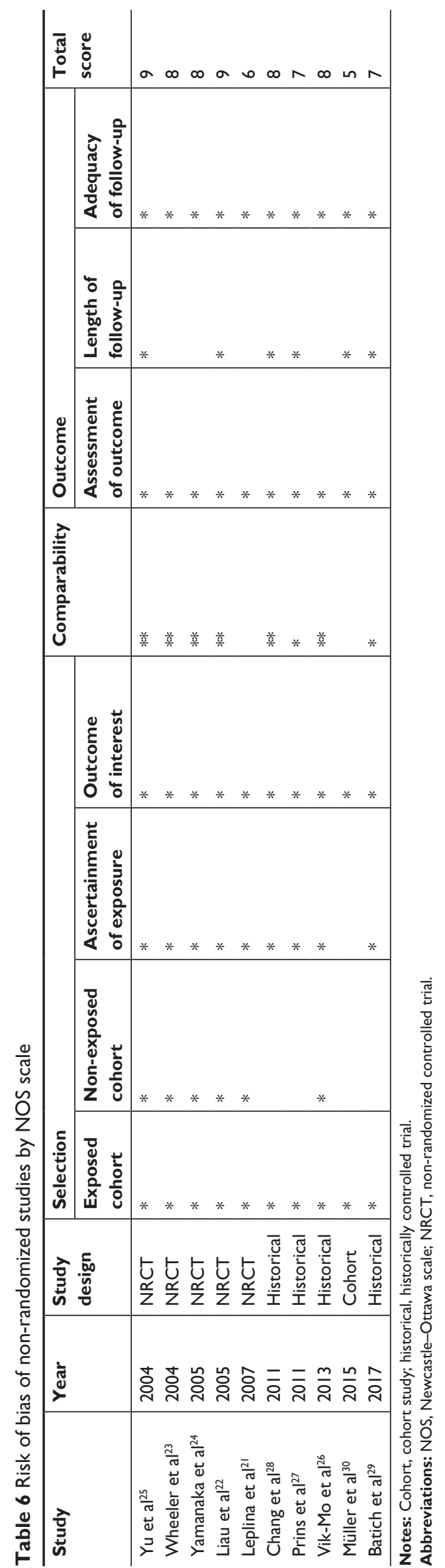

was found after deleting any of the studies, representatively shown in Figure 3 (data from 1-year OS), indicating that no individual study affected the pooled RR significantly.

\section{Publication bias}

Publication bias was assessed by Egger's plot and Begg's test regarding OS and PFS, when studies included were more than ten. Results indicated that no significant difference was found in publication bias regarding OS (Begg's test: $P=0.853$, Egger's test: $P=0.451$, as representatively shown in Figure 4 for 1-year OS).

\section{Discussion}

In this meta-analysis, we evaluated the efficacy of DCs in treatment of HGGs, particularly in terms of the OS, PFS, and AEs. Results indicated that DCs could significantly improve OS and PFS without serious AEs. In the subgroup analysis, DCs were found to be more preferable in NRS than in RCTs in both 1-year OS, 2-year OS, and 3-year OS analysis. Interestingly, no specific difference was found both in 1-year OS and 2-year OS regarding cycles, dosages or routes of injection. Most of the individual subgroups was consistent with the primary outcome. We also performed sensitivity and publication bias analyses to investigate the robustness and bias between studies. In contrast to previous systematic reviews, ${ }^{10,11}$ we collected studies from different regions with different study designs and varied pulsing methods, dosages, cycles, and injection routes for DC administration. With these freshly updated retrievals, we suggest that DC vaccine is safe and effective in improving OS and PFS in HGG patients.

HGGs are some of the most aggressive and refractory brain tumors. Although intensive efforts have been made, the prognosis for HGGs still remains ominous. The poor success of current treatment might partially be due to the translational gap resulting from insufficient consideration of basic concepts of glioma biology in clinical trials. ${ }^{32}$ One of the most important factors that affects the successful treatment of HGGs is the blood-brain barrier (BBB), which prevents the diffusion of anticancer drugs into the central nervous system (CNS). ${ }^{33}$ Fortunately, DC vaccine provides a novel modality as immunotherapy, since CNS is no longer considered as an immune privileged site, but rather an actively regulated site of immune surveillance. ${ }^{34}$ Similar to other leukocytes, DCs can transmigrate the BBB under multiple conditions via different pairs of receptors and ligands. ${ }^{35}$ Our analysis further confirmed that $\mathrm{DC}$ vaccine was effective in prolonging the OS and PFS in HGG patients.

However, there is still a long way to go for DC vaccines to be standardized. As we summarized in this analysis, 


\section{Meta-analysis estimates, given named study is omitted}

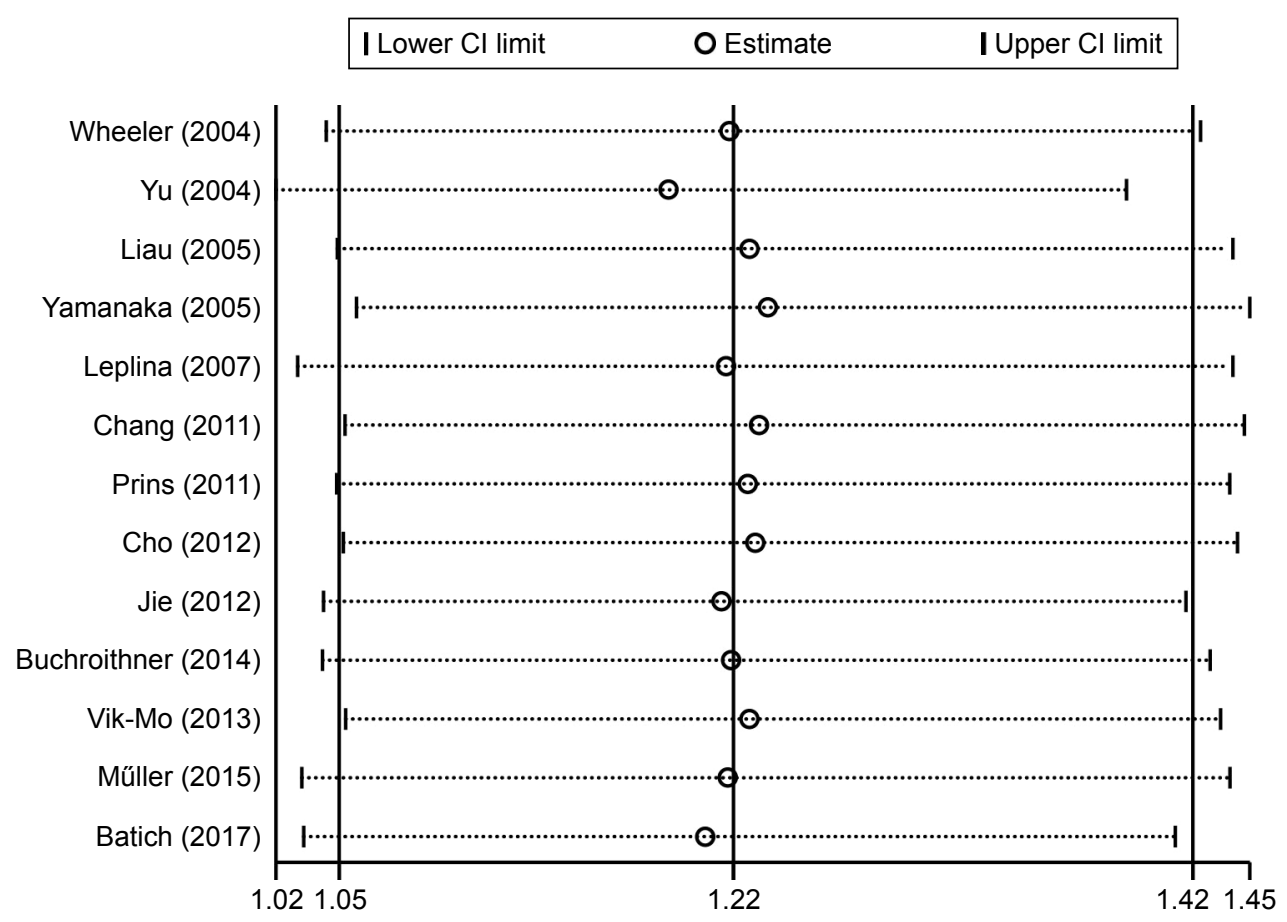

Figure 3 Sensitivity analysis for I-year overall survival.

Tests for publication bias

Begg's test

Adj kendall's score $(P-Q)=10$

SD of score $=16.39$

Number of studies $=13$

$z=0.61$

$\operatorname{Pr}>|z|=0.542$

$z=0.55$ (continuity corrected)

$\operatorname{Pr}>|z|=0.583$ (continuity corrected)

Egger's test

\begin{tabular}{lllllll}
\hline Std_Eff | & Coef & Std Err & $\boldsymbol{t}$ & $\boldsymbol{P}>|\mathbf{t}|$ & \multicolumn{2}{c}{$\mathbf{( 9 5 \%}$ Cl) } \\
\hline Slope | & 0.076584 & 0.1561391 & 0.49 & 0.633 & -0.2670757 & 0.4202438 \\
Bias | & 0.4379253 & 0.5602005 & 0.78 & 0.451 & -0.7950676 & 1.670918
\end{tabular}

\section{Egger's publication bias plot}

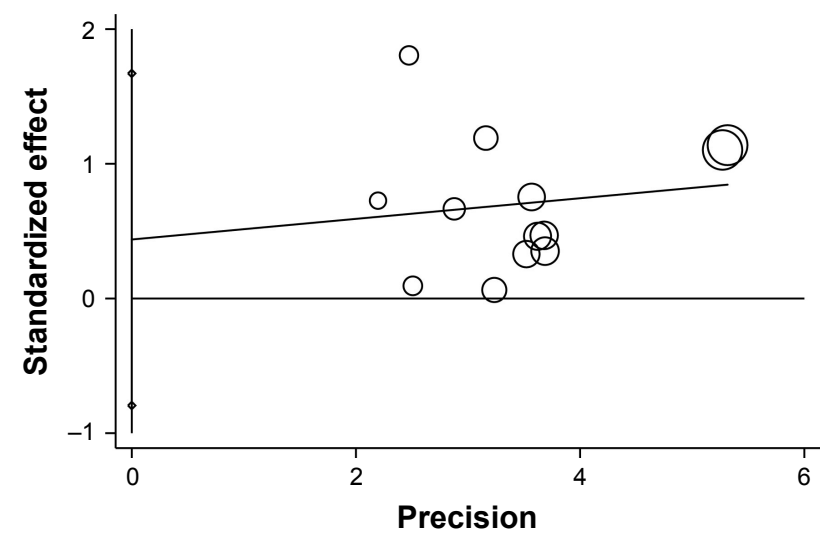

Figure 4 Publication bias analysis for I-year overall survival.
DCs were prepared in multiple ways, then administered via different routes for varied cycles with a broad range of dosages. To be activated, DCs were pulsed with ATL, peptides, DNA constructs or through fusion of DCs with tumor cell lines. ${ }^{36}$ From this meta-analysis, we could not determine which kind of activation of DCs was better than the others. The magnitude of antigen-specific cytotoxic T-lymphocyte responses to DC vaccination is determined by the migration of DCs to lymphoid tissues. However, the migration was greatly affected by the administration route of activated, mature DCs. A variety of injection routes has been investigated, including ID, SC, intravenous, intraperitoneal, intranodal (intralymphatic), and IT. But the optimal route of administration has yet to be determined, although intranodal injection offers the advantage of DCs not needing to migrate, as they are already in close proximity to T-cells in the lymph node. ${ }^{36,37}$ From the data we collected, we could not make a suggestion for the route of DC administration in HGG patients. Neither could we come to a conclusion for the dosages or cycles to be applied.

Our study also had some limitations. Primarily, most of the studies included were NRS, although RCTs are well accepted as the gold standard for intervention studies. ${ }^{38}$ Secondly, the basis for grouping patients in each study slightly differed, which could have affected the analysis of 
OS and PFS in each study to some extent. Thirdly, although there was no statistical publication bias in the overall analysis, only papers published in English with full-text were included in this meta-analysis. This may have resulted in other eligible studies that were unpublished or reported in other languages being left out. In addition, the cohort study and some RCTs without clear report on randomization or allocation concealment, increased the risk of bias in this meta-analysis.

\section{Conclusion}

DC vaccine is safe and effective in reducing mortality and tumor recurrence for patients with HGGs. In the future, double-blind, randomized, placebo-controlled trials in Phase III with adequate follow-up would provide more information on the analysis of DC application in cancers.

\section{Acknowledgment}

This study was supported by Natural Science Foundation of Liaoning Province (201602801).

\section{Author contributions}

HY and YS designed the study, CL and TL collected the data, separately, which was confirmed by BZ and YZ. Data analysis was performed by CL and YS. The first manuscript was written by HY and approved by all the authors. All authors contributed toward data analysis, drafting and critically revising the paper and agree to be accountable for all aspects of the work.

\section{Disclosure}

The authors report no conflicts of interest in this work.

\section{References}

1. Louis DN, Perry A, Reifenberger G, et al. The 2016 World Health Organization Classification of Tumors of the Central Nervous System: a summary. Acta Neuropathol. 2016;131(6):803-820.

2. Stupp R, Mason WP, van den Bent MJ, et al. Radiotherapy plus concomitant and adjuvant temozolomide for glioblastoma. $N$ Engl $J$ Med. 2005;352(10):987-996.

3. Johnson DR, O'Neill BP. Glioblastoma survival in the United States before and during the temozolomide era. J Neurooncol. 2012;107(2): 359-364.

4. Ostrom QT, Gittleman H, Farah P, et al. CBTRUS statistical report: Primary brain and central nervous system tumors diagnosed in the United States in 2006-2010. Neuro Oncol. 2013;15 Suppl 2(Suppl 2): ii1-ii56.

5. Chistiakov DA, Chekhonin IV, Gurina OI, Bobryshev YV, Chekhonin VP. Approaches to improve efficiency of dendritic cell-based therapy of high grade gliomas. Curr Pharm Des. 2016;22(37):5738-5751.

6. Kambayashi T, Laufer TM. Atypical MHC class II-expressing antigenpresenting cells: can anything replace a dendritic cell? Nat Rev Immunol. 2014;14(11):719-730.
7. Banchereau J, Steinman RM. Dendritic cells and the control of immunity. Nature. 1998;392(6673):245-252.

8. Srinivasan VM, Ferguson SD, Lee S, Weathers SP, Kerrigan BCP, Heimberger AB. Tumor vaccines for malignant gliomas. Neurotherapeutics. 2017;14(2):345-357.

9. Anguille S, Smits EL, Lion E, van Tendeloo VF, Berneman ZN. Clinical use of dendritic cells for cancer therapy. Lancet Oncol. 2014;15(7): e257-e267.

10. Cao JX, Zhang XY, Liu JL, et al. Clinical efficacy of tumor antigenpulsed DC treatment for high-grade glioma patients: evidence from a meta-analysis. PLoS One. 2014;9(9):e107173.

11. Wang X, Zhao HY, Zhang FC, Sun Y, Xiong ZY, Jiang XB. Dendritic cell-based vaccine for the treatment of malignant glioma: a systematic review. Cancer Invest. 2014;32(9):451-457.

12. Moher D, Liberati A, Tetzlaff J, Altman DG; Group P, PRISMA Group. Preferred reporting items for systematic reviews and meta-analyses: the PRISMA statement. PLoS Med. 2009;6(7):e1000097.

13. Wells GA, Shea B, O’Connell D, Peterson J, Welch V, Losos M, Tugwell P. The Newcastle-Ottawa Scale (NOS) for assessing the quality if nonrandomized studies in meta-analyses, 2012. Available from: http://wwwohrica/programs/clinical_epidemiology/oxfordasp. Accessed October 17, 2018

14. Higgins JP, Thompson SG, Deeks JJ, Altman DG. Measuring inconsistency in meta-analyses. BMJ. 2003;327(7414):557-560.

15. Begg CB, Mazumdar M. Operating characteristics of a rank correlation test for publication bias. Biometrics. 1994;50(4):1088-1101.

16. Langhorne P. Bias in meta-analysis detected by a simple, graphical test. Prospectively identified trials could be used for comparison with meta-analyses. BMJ. 1998;316(7129):471.

17. Sterne JA, Sutton AJ, Ioannidis JP, et al. Recommendations for examining and interpreting funnel plot asymmetry in meta-analyses of randomised controlled trials. BMJ. 2011;343:d4002.

18. Buchroithner J, Pichler J, Marosi C, et al. Vascular endothelia growth factor targeted therapy may improve the effect of dendritic cell-based cancer immune therapy. Int J Clin Pharmacol Ther. 2014; 52(1):76-77.

19. Cho DY, Yang WK, Lee HC, et al. Adjuvant immunotherapy with whole-cell lysate dendritic cells vaccine for glioblastoma multiforme: a phase II clinical trial. World Neurosurg. 2012;77(5-6):736-744.

20. Jie X, Hua L, Jiang W, Feng F, Feng G, Hua Z. Clinical application of a dendritic cell vaccine raised against heat-shocked glioblastoma. Cell Biochem Biophys. 2012;62(1):91-99.

21. Leplina OY, Stupak VV, Kozlov YP, et al. Use of interferon-alphainduced dendritic cells in the therapy of patients with malignant brain gliomas. Bull Exp Biol Med. 2007;143(4):528-534.

22. Liau LM, Prins RM, Kiertscher SM, et al. Dendritic cell vaccination in glioblastoma patients induces systemic and intracranial T-cell responses modulated by the local central nervous system tumor microenvironment. Clin Cancer Res. 2005;11(15):5515-5525.

23. Wheeler CJ, das A, Liu G, Yu JS, Black KL. Clinical responsiveness of glioblastoma multiforme to chemotherapy after vaccination. Clin Cancer Res. 2004;10(16):5316-5326.

24. Yamanaka R, Homma J, Yajima N, et al. Clinical evaluation of dendritic cell vaccination for patients with recurrent glioma: results of a clinical phase I/II trial. Clin Cancer Res. 2005;11(11):4160-4167.

25. Yu JS, Liu G, Ying H, Yong WH, Black KL, Wheeler CJ. Vaccination with tumor lysate-pulsed dendritic cells elicits antigen-specific, cytotoxic T-cells in patients with malignant glioma. Cancer Res. 2004; 64(14):4973-4979.

26. Vik-Mo EO, Nyakas M, Mikkelsen BV, et al. Therapeutic vaccination against autologous cancer stem cells with mRNA-transfected dendritic cells in patients with glioblastoma. Cancer Immunol Immunother. 2013; 62(9):1499-1509.

27. Prins RM, Soto H, Konkankit V, et al. Gene expression profile correlates with T-cell infiltration and relative survival in glioblastoma patients vaccinated with dendritic cell immunotherapy. Clin Cancer Res. 2011;17(6):1603-1615. 
28. Chang CN, Huang YC, Yang DM, et al. A phase I/II clinical trial investigating the adverse and therapeutic effects of a postoperative autologous dendritic cell tumor vaccine in patients with malignant glioma. J Clin Neurosci. 2011;18(8):1048-1054.

29. Batich KA, Reap EA, Archer GE, et al. Long-term survival in glioblastoma with cytomegalovirus pp65-targeted vaccination. Clin Cancer Res. 2017;23(8):1898-1909.

30. Müller K, Henke G, Pietschmann S, et al. Re-irradiation or re-operation followed by dendritic cell vaccination? Comparison of two differen salvage strategies for relapsed high-grade gliomas by means of a new prognostic model. J Neurooncol. 2015;124(2):325-332.

31. Liberati A, Altman DG, Tetzlaff J, et al. The PRISMA statement for reporting systematic reviews and meta-analyses of studies that evaluate health care interventions: explanation and elaboration. PLoS Med. 2009;6(7):e1000100

32. Guishard AF, Yakisich JS, Azad N, Iyer AKV. Translational gap in ongoing clinical trials for glioma. J Clin Neurosci. 2018;47:28-42.
33. Pardridge WM. The blood-brain barrier: bottleneck in brain drug development. NeuroRx. 2005;2(1):3-14.

34. Negi N, das BK. CNS: Not an immunoprivilaged site anymore but a virtual secondary lymphoid organ. Int Rev Immunol. 2018;37(1):57-68.

35. Sagar D, Foss C, El Baz R, Pomper MG, Khan ZK, Jain P. Mechanisms of dendritic cell trafficking across the blood-brain barrier. JNeuroimmune Pharmacol. 2012;7(1):74-94.

36. Shang N, Figini M, Shangguan J, et al. Dendritic cells based immunotherapy. Am J Cancer Res. 2017;7(10):2091-2102.

37. Bedrosian I, Mick R, Xu S, et al. Intranodal administration of peptidepulsed mature dendritic cell vaccines results in superior CD8+T-cell function in melanoma patients. J Clin Oncol. 2003;21(20):3826-3835.

38. Kaptchuk TJ. The double-blind, randomized, placebo-controlled trial: gold standard or golden calf? J Clin Epidemiol. 2001;54(6):541-549. 


\section{Supplementary materials}

\begin{tabular}{|c|c|c|c|}
\hline Section/topic & $\#$ & Checklist item & $\begin{array}{l}\text { Reported } \\
\text { on page \# }\end{array}$ \\
\hline \multicolumn{4}{|l|}{ TITLE } \\
\hline Title & 1 & Identify the report as a systematic review, meta-analysis, or both. & 1 \\
\hline \multicolumn{4}{|l|}{ ABSTRACT } \\
\hline Structured summary & 2 & $\begin{array}{l}\text { Provide a structured summary including, as applicable: background; objectives; } \\
\text { data sources; study eligibility criteria, participants, and interventions; study } \\
\text { appraisal and synthesis methods; results; limitations; conclusions and } \\
\text { implications of key findings; systematic review registration number. }\end{array}$ & 2 \\
\hline \multicolumn{4}{|l|}{ INTRODUCTION } \\
\hline Rationale & 3 & Describe the rationale for the review in the context of what is already known. & 3 \\
\hline Objectives & 4 & $\begin{array}{l}\text { Provide an explicit statement of questions being addressed with reference to } \\
\text { participants, interventions, comparisons, outcomes, and study design (PICOS). }\end{array}$ & 4 \\
\hline \multicolumn{4}{|l|}{ METHODS } \\
\hline Protocol and registration & 5 & $\begin{array}{l}\text { Indicate if a review protocol exists, if and where it can be accessed } \\
\text { (eg, Web address), and, if available, provide registration information } \\
\text { including registration number. }\end{array}$ & $\mathrm{N} / \mathrm{A}$ \\
\hline Eligibility criteria & 6 & $\begin{array}{l}\text { Specify study characteristics (eg, PICOS, length of follow-up) and report } \\
\text { characteristics (eg, years considered, language, publication status) used as } \\
\text { criteria for eligibility, giving rationale. }\end{array}$ & 4 \\
\hline Information sources & 7 & $\begin{array}{l}\text { Describe all information sources (eg, databases with dates of coverage, } \\
\text { contact with study authors to identify additional studies) in the search and } \\
\text { date last searched. }\end{array}$ & 4 \\
\hline Search & 8 & $\begin{array}{l}\text { Present full electronic search strategy for at least one database, including any } \\
\text { limits used, such that it could be repeated. }\end{array}$ & 4 \\
\hline Study selection & 9 & $\begin{array}{l}\text { State the process for selecting studies (ie, screening, eligibility, included in } \\
\text { systematic review, and, if applicable, included in the meta-analysis). }\end{array}$ & $4-5$ \\
\hline Data collection process & 10 & $\begin{array}{l}\text { Describe method of data extraction from reports (eg, piloted forms, } \\
\text { independently, in duplicate) and any processes for obtaining and confirming } \\
\text { data from investigators. }\end{array}$ & $5-6$ \\
\hline Data items & 11 & $\begin{array}{l}\text { List and define all variables for which data were sought (eg, PICOS, funding } \\
\text { sources) and any assumptions and simplifications made. }\end{array}$ & 6 \\
\hline $\begin{array}{l}\text { Risk of bias in individual } \\
\text { studies }\end{array}$ & 12 & $\begin{array}{l}\text { Describe methods used for assessing risk of bias of individual studies } \\
\text { (including specification of whether this was done at the study or outcome } \\
\text { level), and how this information is to be used in any data synthesis. }\end{array}$ & 6 \\
\hline Summary measures & 13 & State the principal summary measures (eg, risk ratio, difference in means). & 6 \\
\hline Synthesis of results & 14 & $\begin{array}{l}\text { Describe the methods of handling data and combining results of studies, } \\
\text { if done, including measures of consistency }\left(e g, I^{2}\right) \text { for each meta-analysis. }\end{array}$ & 6 \\
\hline Risk of bias across studies & 15 & $\begin{array}{l}\text { Specify any assessment of risk of bias that may affect the cumulative } \\
\text { evidence (eg, publication bias, selective reporting within studies). }\end{array}$ & 11 \\
\hline Additional analyses & 16 & $\begin{array}{l}\text { Describe methods of additional analyses (eg, sensitivity or subgroup analyses, } \\
\text { meta-regression), if done, indicating which were pre-specified. }\end{array}$ & 9,11 \\
\hline \multicolumn{4}{|l|}{ RESULTS } \\
\hline Study selection & 17 & $\begin{array}{l}\text { Give numbers of studies screened, assessed for eligibility, and included in the } \\
\text { review, with reasons for exclusions at each stage, ideally with a flow diagram. }\end{array}$ & $6-7$ \\
\hline Study characteristics & 18 & $\begin{array}{l}\text { For each study, present characteristics for which data were extracted } \\
\text { (eg, study size, PICOS, follow-up period) and provide the citations. }\end{array}$ & 7 \\
\hline Risk of bias within studies & 19 & $\begin{array}{l}\text { Present data on risk of bias of each study and, if available, any outcome level } \\
\text { assessment (see item 12). }\end{array}$ & 11 \\
\hline
\end{tabular}

Figure SI (Continued) 


\begin{tabular}{|l|l|l|l|}
\hline Section/topic & $\#$ & Checklist item & $\begin{array}{l}\text { Reported } \\
\text { on page \# }\end{array}$ \\
\hline Results of individual studies & 20 & $\begin{array}{l}\text { For all outcomes considered (benefits or harms), present, for each study: } \\
\text { (a) simple summary data for each intervention group (b) effect estimates and } \\
\text { confidence intervals, ideally with a forest plot. }\end{array}$ & $8-11$ \\
\hline Synthesis of results & 21 & $\begin{array}{l}\text { Present results of each meta-analysis done, including confidence intervals and } \\
\text { measures of consistency. }\end{array}$ & $8-11$ \\
\hline Risk of bias across studies & 22 & Present results of any assessment of risk of bias across studies (see item 15). & 12 \\
\hline Additional analysis & 23 & $\begin{array}{l}\text { Give results of additional analyses, if done (eg, sensitivity or subgroup } \\
\text { analyses, meta-regression [see item 16]). }\end{array}$ & 12 \\
\hline DISCUSSION & 24 & $\begin{array}{l}\text { Summarize the main findings including the strength of evidence for each main } \\
\text { outcome; consider their relevance to key groups (eg, healthcare providers, users, } \\
\text { and policy makers). }\end{array}$ & $12-13$ \\
\hline Summary of evidence & 25 & $\begin{array}{l}\text { Discuss limitations at study and outcome level (eg, risk of bias), and at } \\
\text { review-level (eg, incomplete retrieval of identified research, reporting bias). }\end{array}$ & $13-14$ \\
\hline Limitations & 26 & $\begin{array}{l}\text { Provide a general interpretation of the results in the context of other evidence, } \\
\text { and implications for future research. }\end{array}$ & 14 \\
\hline Conclusions & 27 & $\begin{array}{l}\text { Describe sources of funding for the systematic review and other support } \\
\text { (eg, supply of data); role of funders for the systematic review. }\end{array}$ & 14 \\
\hline FUNDING & \multicolumn{3}{|l|}{} \\
\hline Funding &
\end{tabular}

Figure SI PRISMA checklist.

Notes: Moher D, Liberati A, Tetzlaff J, Altman DG, The PRISMA Group (2009). Preferred Reporting Items for Systematic Reviews and Meta-Analyses: The PRISMA Statement. PLoS Med. 6(7):el000097. doi: 10.137I/journal.pmed 1000097.' For more information, visit: www.prisma-statement.org.

A

\begin{tabular}{|c|c|c|}
\hline Study & $\operatorname{RR}(95 \% \mathrm{Cl})$ & $\begin{array}{l}\text { Weight } \\
(\%)\end{array}$ \\
\hline Wheeler (2004) & $1.00(0.58-1.72)$ & 5.31 \\
\hline Yu (2004) & $1.37(0.79-2.36)$ & 4.97 \\
\hline Liau (2005) & $1.01(0.66-1.54)$ & 8.64 \\
\hline Yamanaka (2005) & $1.00(0.63-1.58)$ & 7.84 \\
\hline Chang (2011) & $1.08(0.72-1.63)$ & 9.35 \\
\hline Prins (2011) & $1.00(0.61-1.63)$ & 6.63 \\
\hline Cho (2012) & $1.00(0.62-1.61)$ & 6.92 \\
\hline Jie (2012) & $0.96(0.54-1.70)$ & 5.00 \\
\hline Vik-Mo (2013) & $1.00(0.51-1.98)$ & 3.36 \\
\hline Müller (2015) & $1.09(0.87-1.36)$ & 36.06 \\
\hline Batich (2017) & $1.02(0.61-1.71)$ & 5.90 \\
\hline Overall $\left(I^{2}=0.0 \%, P=0.999\right)$ & $1.06(0.93-1.20)$ & 100 \\
\hline
\end{tabular}

C study

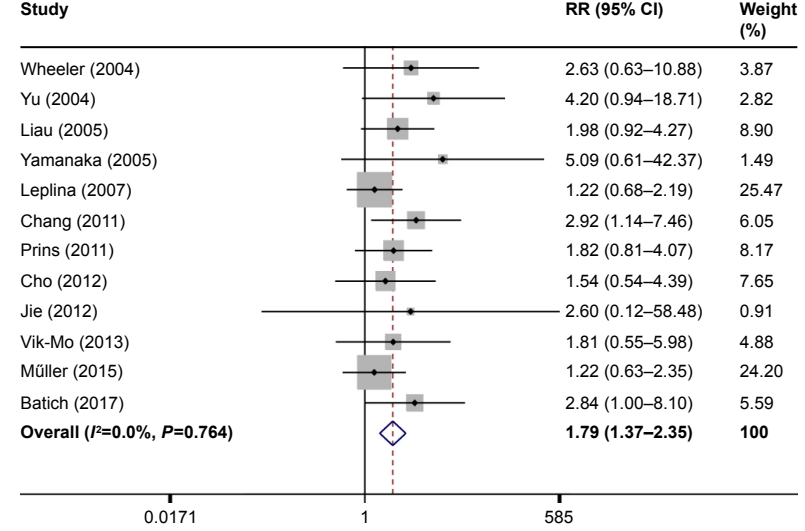

B

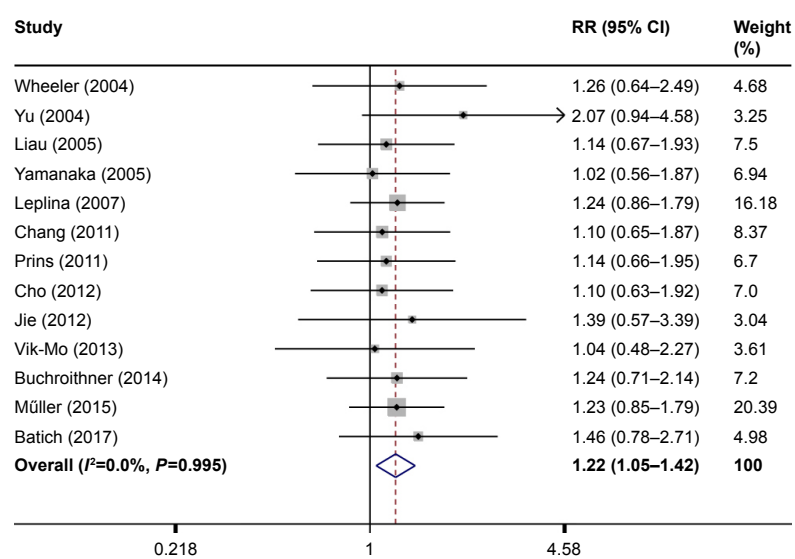

D

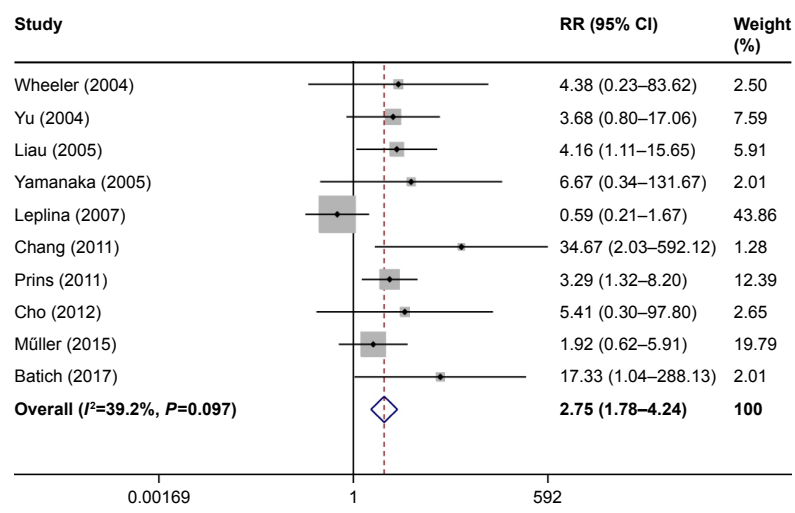

Figure S2 (Continued) 


\section{E}

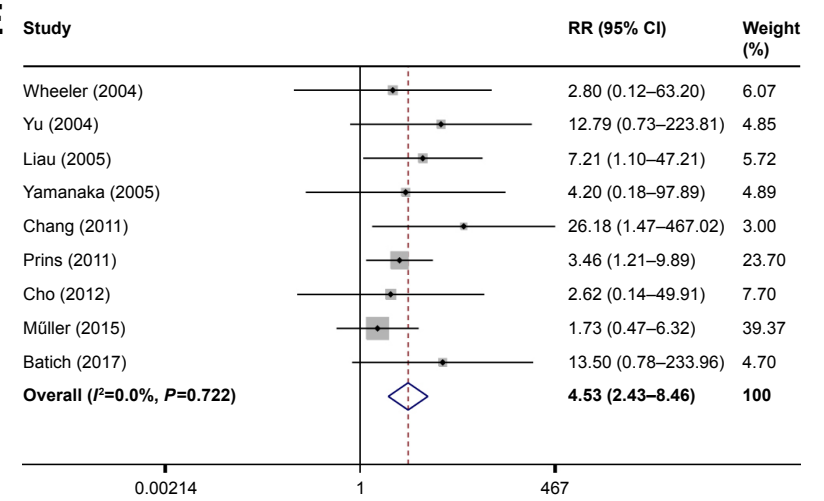

$\mathbf{F}$

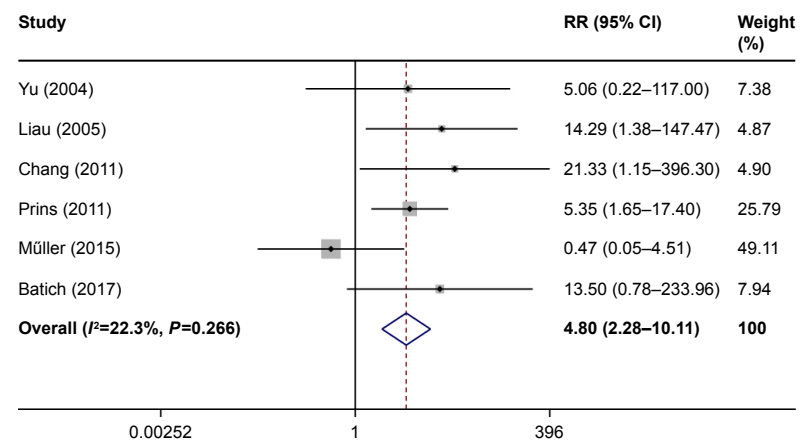

Figure S2 Forest plots for overall survival (OS) analysis of high-grade glioma patients treated with dendritic cells. Note: (A) 0.5-year OS, (B) 1-year OS, (C) 2-year OS, (D) 3-year OS, (E) 4-year OS, (F) 5-year OS.

A stud

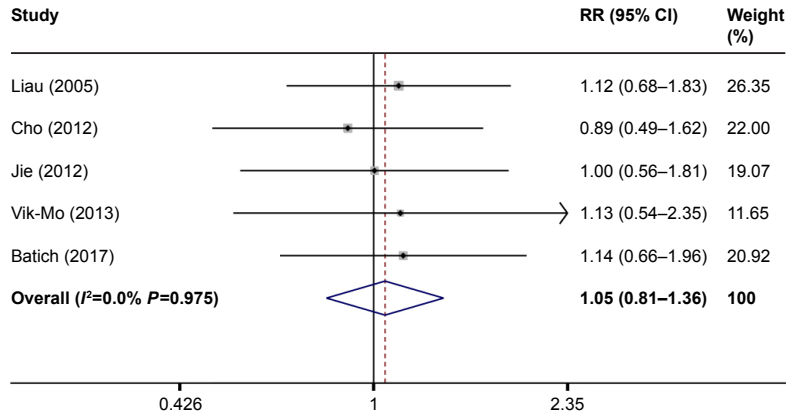

$\mathbf{C}_{\text {sudy }}$

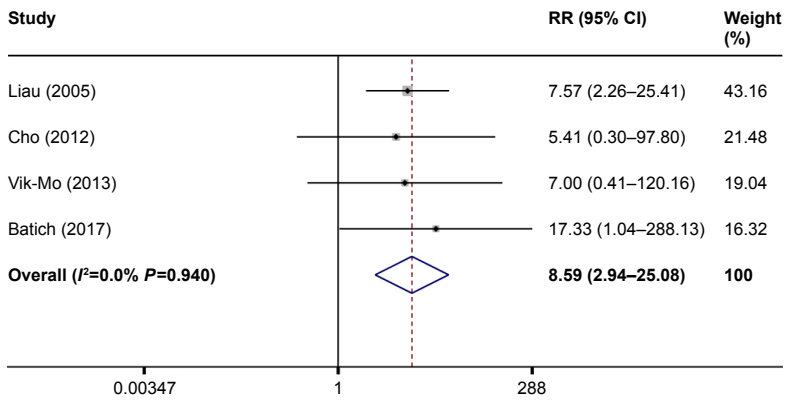

B

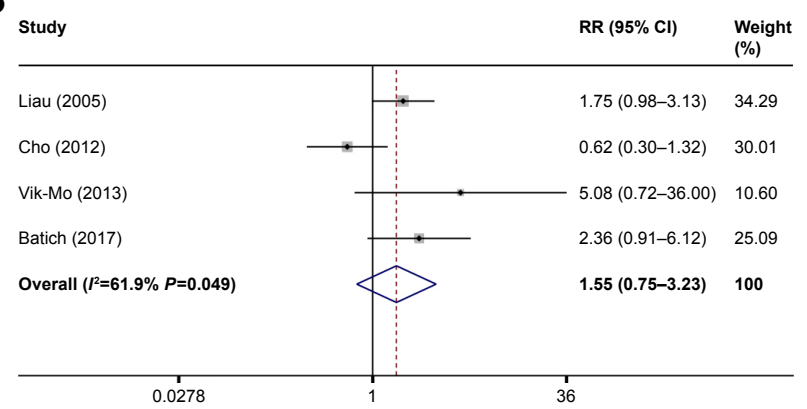

D

\begin{tabular}{|c|c|}
\hline Study & $\mathrm{RR}(95 \% \mathrm{Cl})$ \\
\hline
\end{tabular}

Cho (2012)

Batich (2017)

Overall $\left(I^{2}=0.0 \% P=0.780\right.$

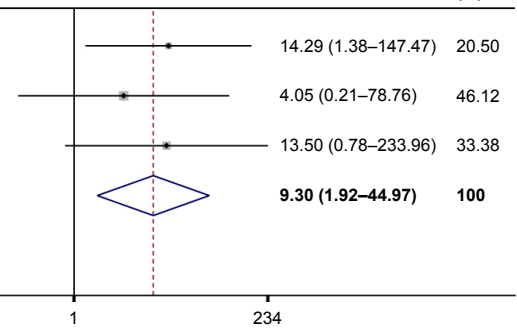

E study

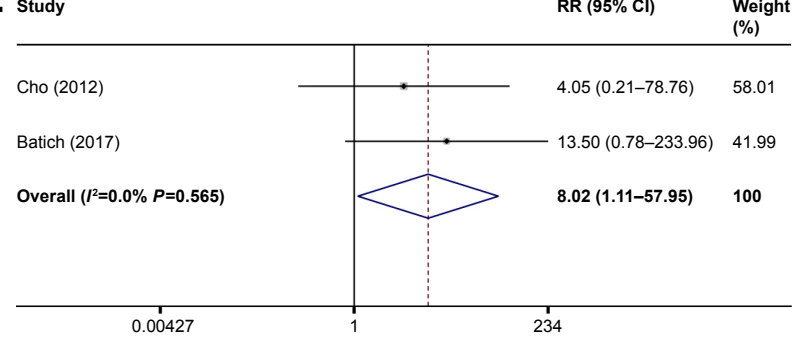

Figure S3 Forest plots for progression-free survival (PFS) analysis of high-grade glioma patients treated with dendritic cells. Notes: (A) 0.5-year PFS, (B) I-year PFS, (C) 2-year PFS, (D) 3-year PFS, (E) 4-year PFS. Weights are from random-effects analysis. 


\section{Reference}

1. Moher D, Liberati A, Tetzlaff J, Altman DG, The PRISMA Group (2009).

Preferred Reporting Items for Systematic Reviews and Meta-Analyses:

The PRISMA Statement. PLoS Med. 6(7):e1000097.

\section{Publish your work in this journal}

OncoTargets and Therapy is an international, peer-reviewed, open access journal focusing on the pathological basis of all cancers, potential targets for therapy and treatment protocols employed to improve the management of cancer patients. The journal also focuses on the impact of management programs and new therapeutic agents and protocols on
Dovepress

patient perspectives such as quality of life, adherence and satisfaction. The manuscript management system is completely online and includes a very quick and fair peer-review system, which is all easy to use. Visit http://www.dovepress.com/testimonials.php to read real quotes from published authors.

\footnotetext{
Submit your manuscript here: http://www.dovepress.com/oncotargets-and-therapy-journal
} 